\title{
Türkiye'deki Pasif Kızlötesi Sensörlü Aydınlatma Armatürlerinin Işıksal ve Elektriksel Performanslarının Değerlendirilmesi
}

\author{
Oğuz Olgun $^{1^{*}}$, İsmail Nakir ${ }^{2}$ \\ ${ }^{1,2}$ Yıldız Teknik Üniversitesi, Elektrik-Elektronik Fakültesi, Elektrik Mühendisliği Bölümü, İstanbul-Türkiye (ORCID: 0000-0002-7745-1673, 0000-0002- \\ 7051-1733)
}

(İlk Geliş Tarihi 18 Haziran 2019 ve Kabul Tarihi 25 Temmuz 2019)

(DOI: 10.31590/ejosat.579306)

ATIF/REFERENCE: Olgun, O. \& Nakir, İ. (2019). Türkiye'deki Pasif Kızılötesi Sensörlü Aydınlatma Armatürlerinin Işıksal ve Elektriksel Performanslarının Değerlendirilmesi. Avrupa Bilim ve Teknoloji Dergisi, (16), 765-775.

Öz

Pasif infrared (PIR) sensörlü armatürler PIR sensör ve armatürün kombine şeklidir. Genellikle ülkemizde, küçük ölçekli projelerin merdiven boşluğu ve antre gibi yerlerinde kullanılmaktadırlar. $\mathrm{Bu}$ sensörler, insanlar bu mahallere girince aydınlatmanın devreye girmesi ve insanlar mahalden ayrıldıktan sonra aydınlatmanın kapatılması amacıyla kullanılırlar. E27 duylu ve LED çipli olmak üzere iki farklı armatür tipi mevcuttur. Bu çalışmada, her iki tipteki PIR sensörlü armatürlerin detaylı 1şıksal ve elektriksel analizleri yapılmışıı. E27 duylu armatür analizlerinde halojen ve LED lamba olmak üzere farklı 1şık kaynağı kullanılmıştır. Ayrıca, kullanılan ışık kaynaklarının da detaylı analizleri yapılmıştır. Elde edilen bulgular çerçevesinde armatürlerin ekonomik analizleri değerlendirilmiş ve sonuç olarak en efektif armatür ve armatür/ş̧ık kaynağı konfigürasyonu belirlenmiştir.

Anahtar kelimeler: PIR sensör, armatür, LED lamba, halojen lamba.

\section{Optical and Electrical Evaluation of Passive Infrared Sensor Equipped Lighting Fixtures in Turkey}

Passive infrared (PIR) sensor equipped lighting fixtures are combination of a PIR sensor and a lighting fixture. They are generally used at staircase and entrance areas of small-scale projects in our country. These PIR sensors are used to activate the lighting when any person enters the zones and turn off the lighting after the person leaves. There are two different types of fixtures, i.e. LED chipped luminaire and E27 lamp-based luminaire. In this work, detailed optical and electrical analyses have been performed for both types of fixtures. Various types of light sources including halogen and LED bulbs have been used in the analysis of E27 lamp-based fixtures. In addition, the analyses of these light sources have also been performed in detail. As a result, economic performance of the luminaires were compared based on the analyzed data and the most effective luminaire as well as luminaire/bulb configurations were determined.

Key words: PIR sensor, lighting fixture, LED lamp, halogen lamp.

\footnotetext{
${ }^{1}$ Sorumlu Yazar: Yıldız Teknik Üniversitesi, Elektrik-Elektronik Fakültesi, Elektrik Mühendisliği Bölümü, İstanbul-Türkiye, ORCID: 0000-00027745-, oguzolgun61@gmail.com
} 


\section{Giriş}

Özellikle yeni nesil aydınlatma armatürleri ve aydınlatma ekipmanları ile ilgili literatürde birçok çalışma mevcuttur. LED, kompakt floresan, floresan ve enkandesan ışık kaynaklarının detaylı analizleri Hasan vd. tarafından yapılmışıtı (Hasan vd., 2017). Bu çalışmada yapılan analiz sonuçlarına göre en yüksek etkinlik değeri LED ışık kaynaklarıyla elde edilmiştir. Ayrıca, enkandesan 1şık kaynaklarının daha yüksek güç faktörü değerine sahip olduğu ve LED lambaların toplam harmonik distorsiyonu (THD) değerlerinin floresan ve enkandesan 1şık kaynaklarına göre daha yüksek olduğu tespit edilmiştir. Ancak bu lambaların yüksek güç tüketim değerleri sebebiyle LED lambaya karşı seçilecek birer alternatif olamadıkları görülmektedir. Ayrıca LED lambaların güç faktörü ve THD değerlerinin kabul edilebilir seviyelerde yer aldığı yine aynı çalışma ile tespit edilmiştir.

Retrofit (yenileme) uygulamaları için tasarlanan LED lamba ve LED tüplerin enerji kalitelerinin Brezilya standartlarına uygunluğu Oliveira vd. tarafindan incelenmiştir (Oliveira vd., 2016). İnceleme sonuçlarına göre LED lambaların standartlar çerçevesinde olduğu, LED tüplerin ise standartlara uymadığı tespit edilmiştir.

Enkandesan lamba kullanılan bir armatüre LED ve kompakt floresan lamba (CFL) retrofitlerinin uygulanması ile elde edilen sonuçlar Raditschova ve Gasparovsky tarafından incelenmiştir (Raditschova ve Gasparovsky, 2016). Elde edilen sonuçlara göre LED retrofitin başarılı olduğu, CFL retrofitin ise istenen aydınlatma performansını yakalayamadığı tespit edilmiştir.

LED retrofit ile elde edilecek tasarruf miktarı İtalya'daki bir alışveriş merkezi projesi üzerine kurgulanarak sonuçlar incelenmiştir (Raimondi vd., 2018). Bu çalışma ile LED retrofit uygulamasının uygulama maliyetini 5 yıldan kısa bir sürede amorti ettiği tespit edilmiştir. Ayrıca retrofite ilave olarak alışveriş merkezi aydınlatma sistemine otomasyon sistemi akuple edilmiştir. İlave edilen otomasyon sisteminin de 5 yıldan kısa bir sürede yatırım maliyetini amorti ettiği tespit edilmiştir.

Alternatifli bir retrofit senaryosu ise bir yönetim binası projesi üzerine kurgulanmıştır (Oleksijs ve Sauhatas, 2016). Bu çalışmada, 15 yıllık süre ve sadece mesai saatlerinde armatürlerin çalışması dikkate alınarak mevcut lambaların sadece LED retrofiti, mevcut lambaların sadece PIR sensörler ile kontrolü veya üçüncü seçenek olarak LED retrofit ve PIR sensörünün birlikte uygulanması seçenekleri kurgulanmıştır. Yapılan incelemelerde en efektif çözümün LED retrofit olduğu ve bunu LED retrofit ve PIR sensör uygulamasının beraber uygulandığı sistemin izlediği tespit edilmiştir. Mevcut lambaların PIR sensörlerle kontrolü seçeneğinin ise en az ekonomik olan çözüm olduğu sonucuna varılmıştır.

PIR sensörlü armatürler bekleme anında 1 ile 3 watt (W) arasında enerji tüketmektedirler. Armatürlere ultrakapasitör ve basit ilave devreler eklenerek bekleme anındaki enerji tüketimi 0,004W'a kadar düşürülmüştür (Tsai vd., 2011). Bir diğer çalışmada ise çeşitli optimizasyonlarla bekleme anındaki tüketim 0,001W'a çekilmiş ve armatüre eklenen fotovoltaik dizi ile 150 lüks (lx) aydınlık düzeyinde armatürün tüketimi $0 \mathrm{~W}$ 'a indirilerek bekleme anındaki enerji tüketimi tamamen ortadan kaldırılmıştır (Tsai vd., 2013).

Literatürde yer alan bu çalışmalar değişik ışık kaynaklarının incelenmesi, enkandesan lamba kullanan armatürlere LED retrofit uygulamaları ve PIR sensörlü armatürlerin efektif hale getirilmesi üzerinde yoğunlaşmıştır. Ancak mevcut PIR sensörlü armatürlerin detaylı analizleri ile bu armatürlere yapılmış bir retrofit çalışmasına literatürde henüz yer verilmemiştir. Bu çalışmada ülkemizde bulunan PIR sensörlü armatürlerin detaylı ışıksal ve elektriksel incelemesi yapılmıştır. İncelenen armatürler kendinden led çipli ve E27 duylu olmak üzere iki farklı tiptedir. E27 duylu tipler hem halojen hem de LED lambalar kullanılarak incelenmiştir. Bu inceleme sonucu retrofit uygulamalarının efektiflik durumunun da ortaya konması amaçlanmıştır. İncelemelerin temel amacı en efektif PIR sensörlü armatür ve armatür/şsık kaynağı kombinasyonunun tespit edilmesidir.

\section{PIR Sensörlü Armatürler}

PIR sensör kızılötesi 1şınımı algılamaya yarayan sensör çeşididir. İnsan vücudu yaklaşık 100W'lık kızılötesi 1şınım yapar. PIR sensör bu ışınımı algılayarak dijital çıkış verir (Juntunen vd., 2018). PIR sensör; sensör, güç ve kontrol devreleri ile fresnel lensten oluşmaktadır. Fresnel lens, algılanan kızılötesi ışınımın sensöre odaklanarak sensörün daha hassas ve daha geniş algılama mesafesine ulaşmasını sağlar. Algılama yapıldığı zaman kontrol devresi dijital çıkış verir. PIR sensörün temel yapısı Şekil 1'de gösterilmiştir.

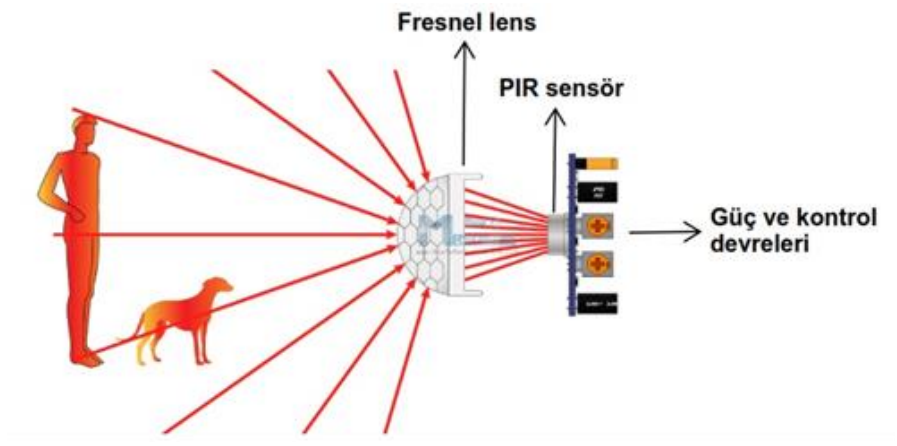

Şekil 1. PIR sensörün yaptsı

PIR sensörlü armatür PIR sensör ve aydınlatma armatürünün biraraya gelmesinden oluşmaktadır. PIR sensör kızılötesi algılama yaptı̆̆ı zaman dijital çıkış verir ve armatür ışık vermeye başlar. Genelde aydınlatma anahtarı kullanımının zahmetli olduğu merdiven boşlukları, uzun koridorlar ve antre gibi yerlerde kullanılırlar. PIR sensörlü armatürün yapısı Şekil 2'de gösterilmiştir. 


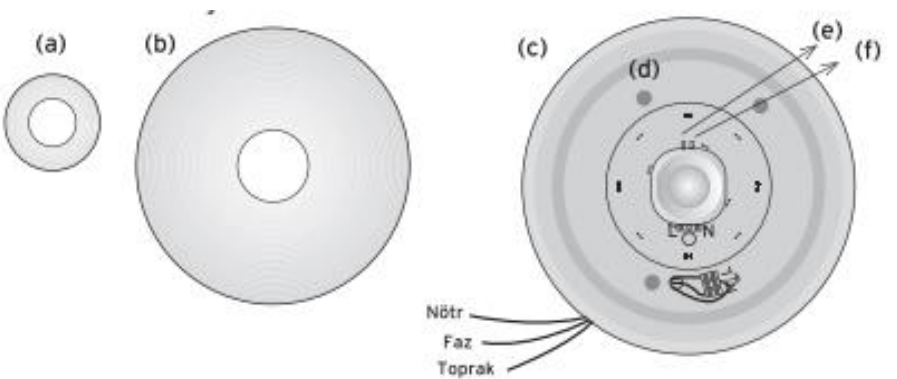

(a) Tutturma rondelası, (b) Cam kapak, (c) Ana gövde, (d) Tavan montaj delikleri,(e) Gün ışı̆̆ı ayar trimpotu, (f) Zaman ayar trimpotu Şekil 2. PIR sensörlü armatürün yapısı

Armatürler dairesel tiptedir. Tutturma rondelası çevirilip çıkarıldıktan sonra cam kapağın sökülmesi ile armatüre müdahale edilebilmektedir. PIR sensör armatürün ortasında yer almaktadır ve $360^{\circ}$ algılama yapabilmektedir. Sensörde ayrıca gün $1 s ̧ ı \breve{g} 1$ ve zaman ayarı yer almaktadır. Gün ışığı ayarı gündüze alındığında PIR sensör gece veya gündüz algılama yaptığı zaman armatür ışık vermektedir. Gün 1şığı ayarı gece konumundayken PIR sensör gündüz algılama yaptığında armatür 1şık vermemekte; sadece gece yapılan algılamalarda 1şık vermektedir. Zaman ayarı armatürün (üreticiye göre değişmekle birlikte) 10 saniye ile 5 dakika arasındaki 1şık verme süresini ayarlamaya yaramaktadır. Armatürün montaj detayı Şekil 3 ’te verilmiştir.

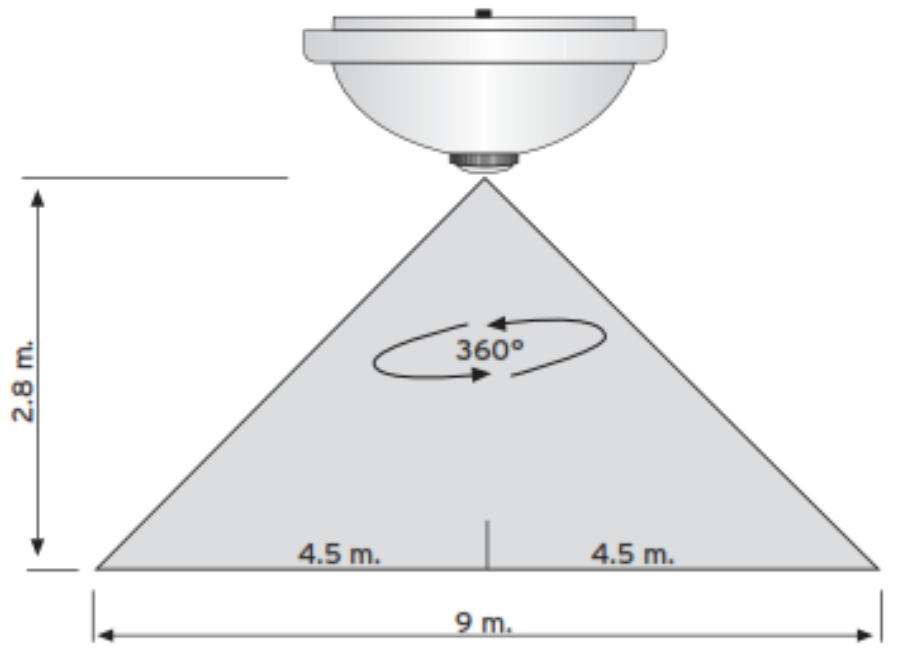

Şekil 3. PIR sensörlü armatürün montaj detayı

Armatürler sıva üstü montaja uygundur. Yaklaşık montaj yüksekliği 3 metredir. Algılama kapsamları da yaklaşık 9 metre çapında dairesel bir alandır. Koruma sınıfları IP 20 olduğu için nemli yerlere ve dış mekanlara montajları uygun değildir.

Bu çalışmada Türkiye piyasasında bulunan 14 adet armatür analiz edilmiştir. Analiz edilen armatürlere ait görseller Şekil 4'te verilmiştir. Bu armatürlerden 10 tanesi (1-10 arası) 2 adet E27 duya sahiptir. Diğer 4'ü ise (11-14 arası) kendi LED çiplerine sahiptirler. Armatürler sac kasalıdır. İçleri ve dışları beyaz boyalıdır. Armatürlerde reflektör yoktur. Bir kısmının camı buzlu, bir kısmının camı ise hem buzlu hem de boyalıdır.

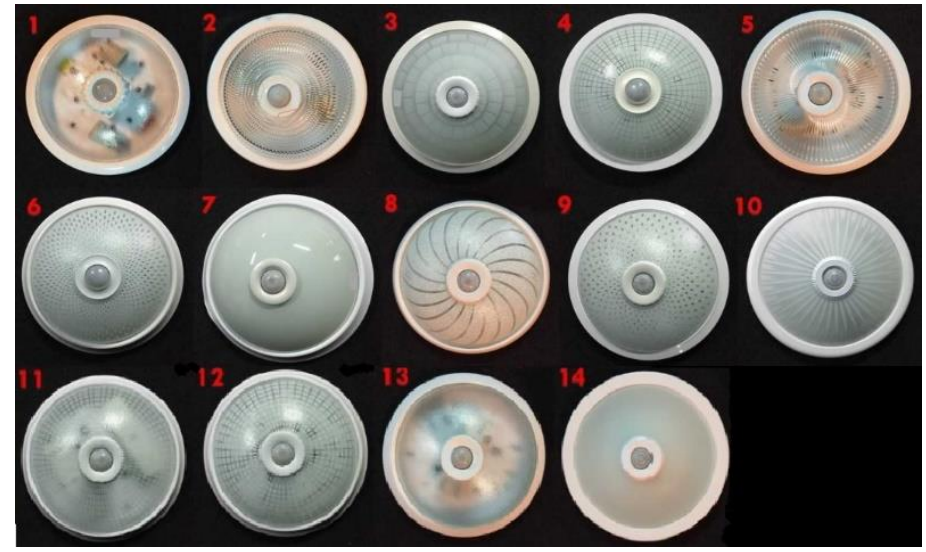

Şekil 4. Analiz edilen armatürler

\section{E27 Duylu PIR Sensörlü Armatürlerde Kullanılan Işık Kaynakları ve Analizleri}

E27 duylu armatür analizlerinde 1 adet halojen lamba, 2 adet de LED lamba kullanılmıştır. Halojen lamba 30W, LED lambalar da sirasıyla 9,5W ve 8W güce sahiptir. Her E27 duylu armatür bu 3 1şık kaynağı ile ayrı ayrı test edilerek sonuçlar incelenmiştir. Bu testler öncesinde 1şık kaynaklarının detaylı analizleri yapılarak elde edilen bulgular armatür testlerinde kullanılmış olup, lamba ölçüm 
sonuçları Çizelge 1'de verilmiştir.

Çizelge 1. Işık kaynaklarının elektriksel ve 1şıksal ölçüm sonuçları

\begin{tabular}{|l|c|c|c|}
\hline Değerlen dirme Kriterleri & Lamba-1 & Lamba-2 & Lamba-3 \\
\hline Lamba Tipi & Halojen & LED & LED \\
\hline Lamba Gücü (Fabrika Verisi) & $30 \mathrm{~W}$ & $9,5 \mathrm{~W}$ & $8 \mathrm{~W}$ \\
\hline Ölçülen Lamba Gücü & $27,61 \mathrm{~W}$ & $9,46 \mathrm{~W}$ & $7,66 \mathrm{~W}$ \\
\hline Güç Faktörü & 1,00 & 0,54 & 0,58 \\
\hline Işı Akısı $(\phi)$ & $255,661 \mathrm{~m}$ & $805,12 \mathrm{~lm}$ & $665,401 \mathrm{~m}$ \\
\hline Etkinlik (Eff) & $9,261 \mathrm{~m} / \mathrm{W}$ & $85,11 \mathrm{~m} / \mathrm{W}$ & $86,87 \mathrm{~lm} / \mathrm{W}$ \\
\hline Renksel Geriverim İndeksi (CRI) & 99,9 & 85,4 & 83,6 \\
\hline Renk Sicaklığı $\left(\mathrm{T}_{\mathrm{c}}\right)$ & $2612 \mathrm{~K}$ & $6253 \mathrm{~K}$ & $6455 \mathrm{~K}$ \\
\hline
\end{tabular}

Ölçüm sonuçlarına göre tüketilen güç, üretilen ışık akısı ve etkinlik değerleri konusunda LED lambaların halojen lambaya karşı ezici bir üstünlüğü bulunmaktadır. Güç faktörü ve renksel geriverim konularında ise halojen lamba üstündür. Ancak LED lambaların 80 üzeri olan renksel geriverim değeri gayet yeterli bir performans sergilemekte ve düşük güç faktörü konusu basit bir kompanzasyon sistemi ile çözülebilmektedir ki; oldukça düşük tüketim değerleri bu iki maddeyi de ihmal edilebilir hale getirmektedir. Renk sıcaklığı olarak LED lambalar soğuk beyaz, halojen lamba ise sıcak beyaz renkte ş̧ık vermektedir.

\section{PIR Sensörlü Armatür Analizleri}

PIR sensörlü armatürlerin ışı vermedikleri bekleme anındaki elektriksel değerleri ölçülmüş olup ölçüm sonuçları Çizelge 2'de verilmiş̧ir.

Çizelge 2. Armatürlerin bekleme anındaki elektriksel ölçüm sonuçları

\begin{tabular}{|r|l|c|c|c|}
\hline No. & Armatür Cinsi & $\begin{array}{c}\text { Aktif Güç } \\
\text { (W) }\end{array}$ & $\begin{array}{c}\text { Reaktif } \\
\text { Güç (VAr) }\end{array}$ & $\begin{array}{c}\text { Gü̈c } \\
\text { Faktörü }\end{array}$ \\
\hline $\mathbf{1}$ & Armatür-1 & 1,20 & 7,75 & 0,15 \\
\hline $\mathbf{2}$ & Armatür-2 & 1,10 & 7,75 & 0,14 \\
\hline $\mathbf{3}$ & Armatür-3 & 0,85 & 6,60 & 0,13 \\
\hline $\mathbf{4}$ & Armatür-4 & 0,70 & 5,00 & 0,14 \\
\hline $\mathbf{5}$ & Armatür-5 & 0,70 & 4,70 & 0,15 \\
\hline $\mathbf{6}$ & Armatür-6 & 0,70 & 5,10 & 0,14 \\
\hline $\mathbf{7}$ & Armatür-7 & 0,80 & 5,50 & 0,14 \\
\hline $\mathbf{8}$ & Armatür-8 & 0,80 & 6,40 & 0,12 \\
\hline $\mathbf{9}$ & Armatür-9 & 0,80 & 6,00 & 0,13 \\
\hline $\mathbf{1 0}$ & Armatür-10 & 0,60 & 4,80 & 0,12 \\
\hline $\mathbf{1 1}$ & Armatür-11 & 1,00 & 7,00 & 0,14 \\
\hline $\mathbf{1 2}$ & Armatür-12 & 0,70 & 6,90 & 0,10 \\
\hline $\mathbf{1 3}$ & Armatür-13 & 1,00 & 6,70 & 0,15 \\
\hline $\mathbf{1 4}$ & Armatür-14 & 0,75 & 0,50 & 0,83 \\
\hline
\end{tabular}

Sonuçlar incelendiğinde armatürlerin aktif güç tüketimlerinin $0.60-1.20 \mathrm{~W}$, reaktif güç tüketimlerinin $0.50-7.75 \mathrm{VAr}$ ve güç faktörlerinin 0.12-0.83 arasında olduğu tespit edilmiştir. Burada bir noktaya dikkat çekmemiz gerekiyor. Armatür-14 0,50VAr ile en düşük reaktif güç tüketimine, 0.83 ile de en yüksek güç faktörüne sahiptir. Armatür-14 dışındaki armatürlere bakacak olursak bunların reaktif güç tüketimleri 4.70-7.75VAr, güç faktörleri de 0.12-0.15 aralığındadır. Armatür-14’te şebekeden çekilen reaktif gücü sınırlayan ilave devreler kullanıldığı düşünülmektedir.

PIR sensörlü armatürlerin çalışma anındaki elektriksel değerleri de ölçülmüş olup, ölçüm sonuçları ise Çizelge 3’te verilmiştir. 


\section{Avrupa Bilim ve Teknoloji Dergisi}

Çizelge 3. Armatürlerin çalışma anındaki elektriksel ölçüm sonuçları

\begin{tabular}{|r|l|l|c|c|c|}
\hline No. & $\begin{array}{c}\text { Armatür } \\
\text { Cinsi }\end{array}$ & Lamba & $\begin{array}{c}\text { Aktif Güc } \\
\text { (W) }\end{array}$ & $\begin{array}{c}\text { Reaktif } \\
\text { Güç (VAr) }\end{array}$ & $\begin{array}{c}\text { Güç } \\
\text { Faktörü }\end{array}$ \\
\hline $\mathbf{1}$ & Armatür-1 & Lamba-1 & 56,35 & 10,35 & 0,98 \\
\hline $\mathbf{2}$ & Armatür-1 & Lamba-2 & 19,97 & 37,52 & 0,47 \\
\hline $\mathbf{3}$ & Armatür-1 & Lamba-3 & 16,24 & 30,09 & 0,47 \\
\hline $\mathbf{4}$ & Armatür-2 & Lamba-1 & 56,10 & 12,85 & 0,97 \\
\hline $\mathbf{5}$ & Armatür-2 & Lamba-2 & 19,96 & 39,87 & 0,45 \\
\hline $\mathbf{6}$ & Armatür-2 & Lamba-3 & 16,23 & 32,58 & 0,45 \\
\hline $\mathbf{7}$ & Armatür-3 & Lamba-1 & 56,19 & 7,86 & 0,99 \\
\hline $\mathbf{8}$ & Armatür-3 & Lamba-2 & 19,57 & 34,79 & 0,49 \\
\hline $\mathbf{9}$ & Armatür-3 & Lamba-3 & 15,87 & 27,52 & 0,50 \\
\hline $\mathbf{1 0}$ & Armatür-4 & Lamba-1 & 56,02 & 6,11 & 0,99 \\
\hline $\mathbf{1 1}$ & Armatür-4 & Lamba-2 & 19,35 & 32,99 & 0,51 \\
\hline $\mathbf{1 2}$ & Armatür-4 & Lamba-3 & 15,67 & 25,78 & 0,52 \\
\hline $\mathbf{1 3}$ & Armatür-5 & Lamba-1 & 55,96 & 5,86 & 0,99 \\
\hline $\mathbf{1 4}$ & Armatür-5 & Lamba-2 & 19,25 & 32,91 & 0,50 \\
\hline $\mathbf{1 5}$ & Armatür-5 & Lamba-3 & 15,57 & 25,57 & 0,52 \\
\hline $\mathbf{1 6}$ & Armatür-6 & Lamba-1 & 55,72 & 6,20 & 0,99 \\
\hline $\mathbf{1 7}$ & Armatür-6 & Lamba-2 & 19,32 & 33,11 & 0,50 \\
\hline $\mathbf{1 8}$ & Armatür-6 & Lamba-3 & 15,65 & 25,97 & 0,52 \\
\hline $\mathbf{1 9}$ & Armatür-7 & Lamba-1 & 56,21 & 7,11 & 0,99 \\
\hline $\mathbf{2 0}$ & Armatür-7 & Lamba-2 & 19,40 & 34,05 & 0,50 \\
\hline $\mathbf{2 1}$ & Armatür-7 & Lamba-3 & 15,74 & 26,86 & 0,51 \\
\hline $\mathbf{2 2}$ & Armatür-8 & Lamba-1 & 55,67 & 8,00 & 0,99 \\
\hline $\mathbf{2 3}$ & Armatür-8 & Lamba-2 & 19,43 & 35,05 & 0,48 \\
\hline $\mathbf{2 4}$ & Armatür-8 & Lamba-3 & 15,75 & 27,75 & 0,49 \\
\hline $\mathbf{2 5}$ & Armatür-9 & Lamba-1 & 56,45 & 7,41 & 0,99 \\
\hline $\mathbf{2 6}$ & Armatür-9 & Lamba-2 & 19,43 & 34,27 & 0,49 \\
\hline $\mathbf{2 7}$ & Armatür-9 & Lamba-3 & 15,74 & 27,09 & 0,50 \\
\hline $\mathbf{2 8}$ & Armatür-10 & Lamba-1 & 56,14 & 6,01 & 0,99 \\
\hline $\mathbf{2 9}$ & Armatür-10 & Lamba-2 & 19,23 & 32,92 & 0,50 \\
\hline $\mathbf{3 0}$ & Armatür-10 & Lamba-3 & 15,57 & 25,77 & 0,52 \\
\hline $\mathbf{3 1}$ & Armatür-11 & - & 7,50 & 14,90 & 0,45 \\
\hline $\mathbf{3 2}$ & Armatür-12 & - & 7,30 & 14,90 & 0,44 \\
\hline $\mathbf{3 3}$ & Armatür-13 & - & 8,00 & 25,30 & 0,30 \\
\hline $\mathbf{3 4}$ & Armatür-14 & - & 7,60 & 2,60 & 0,95 \\
\hline & & & & \\
\hline
\end{tabular}

Sonuçlar incelendiğinde en düşük aktif güç tüketimine LED çipli armatürlerin sahip olduğu görülmektedir. LED çipli armatürleri aktif güç tüketiminde sırasıyla Lamba-3 kullanan, Lamba-2 kullanan ve Lamba-1 kullanan armatürler izlemektedir. Reaktif güç tüketimlerinde ise sıralama en az tüketenden en çok tüketene doğru Lamba-1 kullanan, LED çipli, Lamba-3 kullanan ve Lamba-2 kullanan armatürler şeklindedir. Güç faktörü sıralaması da büyükten küçüğe doğru Lamba-1 kullanan, Lamba-3 kullanan, Lamba-2 kullanan ve LED çipli armatürler şeklindedir. Bu değerlendirmedeki en önemli parametre aktif güç tüketimidir. Reaktif güç tüketimi ve güç faktörü basit kompanzasyon sistemleri ile kolayca çözülebilmektedir. Bu sebeple LED çipli armatürler düşük aktif güç tüketimleri ile öne çıkmaktadırlar.

PIR sensörlü armatürlerin bekleme ve çalışma anındaki toplam harmonik distorsiyonu (THD) değerleri ölçülmüştür. Ölçüm sonuçları Çizelge 4 'te verilmiştir. 
European Journal of Science and Technology

Çizelge 4. Armatürlerin THD ölçüm sonuçlart

\begin{tabular}{|c|l|l|c|c|}
\hline No. & $\begin{array}{l}\text { Armatür } \\
\text { Cinsi }\end{array}$ & Lamba & $\begin{array}{c}\text { THD } \\
\text { Bekleme }\end{array}$ & $\begin{array}{c}\text { THD } \\
\text { Çalışma }\end{array}$ \\
\hline $\mathbf{1}$ & Armatür-1 & Lamba-1 & $30,60 \%$ & $4,80 \%$ \\
\hline $\mathbf{2}$ & Armatür-1 & Lamba-2 & $30,60 \%$ & $105,50 \%$ \\
\hline $\mathbf{3}$ & Armatür-1 & Lamba-3 & $30,60 \%$ & $90,10 \%$ \\
\hline $\mathbf{4}$ & Armatür-2 & Lamba-1 & $29,50 \%$ & $5,00 \%$ \\
\hline $\mathbf{5}$ & Armatür-2 & Lamba-2 & $29,50 \%$ & $100,40 \%$ \\
\hline $\mathbf{6}$ & Armatür-2 & Lamba-3 & $29,50 \%$ & $83,00 \%$ \\
\hline $\mathbf{7}$ & Armatür-3 & Lamba-1 & $30,50 \%$ & $4,20 \%$ \\
\hline $\mathbf{8}$ & Armatür-3 & Lamba-2 & $30,50 \%$ & $113,50 \%$ \\
\hline $\mathbf{9}$ & Armatür-3 & Lamba-3 & $30,50 \%$ & $97,70 \%$ \\
\hline $\mathbf{1 0}$ & Armatür-4 & Lamba-1 & $29,60 \%$ & $3,80 \%$ \\
\hline $\mathbf{1 1}$ & Armatür-4 & Lamba-2 & $29,60 \%$ & $118,60 \%$ \\
\hline $\mathbf{1 2}$ & Armatür-4 & Lamba-3 & $29,60 \%$ & $103,70 \%$ \\
\hline $\mathbf{1 3}$ & Armatür-5 & Lamba-1 & $30,10 \%$ & $3,80 \%$ \\
\hline $\mathbf{1 4}$ & Armatür-5 & Lamba-2 & $30,10 \%$ & $118,90 \%$ \\
\hline $\mathbf{1 5}$ & Armatür-5 & Lamba-3 & $30,10 \%$ & $103,80 \%$ \\
\hline $\mathbf{1 6}$ & Armatür-6 & Lamba-1 & $30,10 \%$ & $3,90 \%$ \\
\hline $\mathbf{1 7}$ & Armatür-6 & Lamba-2 & $30,10 \%$ & $119,40 \%$ \\
\hline $\mathbf{1 8}$ & Armatür-6 & Lamba-3 & $30,10 \%$ & $103,40 \%$ \\
\hline $\mathbf{1 9}$ & Armatür-7 & Lamba-1 & $31,10 \%$ & $4,10 \%$ \\
\hline $\mathbf{2 0}$ & Armatür-7 & Lamba-2 & $31,10 \%$ & $116,30 \%$ \\
\hline $\mathbf{2 1}$ & Armatür-7 & Lamba-3 & $31,10 \%$ & $101,10 \%$ \\
\hline $\mathbf{2 2}$ & Armatür-8 & Lamba-1 & $30,40 \%$ & $4,30 \%$ \\
\hline $\mathbf{2 3}$ & Armatür-8 & Lamba-2 & $30,40 \%$ & $115,10 \%$ \\
\hline $\mathbf{2 4}$ & Armatür-8 & Lamba-3 & $30,40 \%$ & $98,80 \%$ \\
\hline $\mathbf{2 5}$ & Armatür-9 & Lamba-1 & $29,50 \%$ & $4,10 \%$ \\
\hline $\mathbf{2 6}$ & Armatür-9 & Lamba-2 & $29,50 \%$ & $117,70 \%$ \\
\hline $\mathbf{2 7}$ & Armatür-9 & Lamba-3 & $29,50 \%$ & $100,70 \%$ \\
\hline $\mathbf{2 8}$ & Armatür-10 & Lamba-1 & $28,40 \%$ & $3,80 \%$ \\
\hline $\mathbf{2 9}$ & Armatür-10 & Lamba-2 & $28,40 \%$ & $120,50 \%$ \\
\hline $\mathbf{3 0}$ & Armatür-10 & Lamba-3 & $28,40 \%$ & $105,20 \%$ \\
\hline $\mathbf{3 1}$ & Armatür-11 & - & $29,40 \%$ & $52,20 \%$ \\
\hline $\mathbf{3 2}$ & Armatür-12 & - & $26,10 \%$ & $53,40 \%$ \\
\hline $\mathbf{3 3}$ & Armatür-13 & $-60 \%$ & $26,30 \%$ \\
\hline $\mathbf{3 4}$ & Armatür-14 & $-70 \%$ & $29,30 \%$ \\
\hline
\end{tabular}

Sonuçlar incelendiğinde bekleme anındaki THD değerlerinin armatürlerde genel olarak \%30 mertebesinde olduğu tespit edilmiştir. Armatür-14 \%123,70 ile bu genellemeyi bozmaktadır. Çalışma anında ise THD değerleri sıralaması küçükten büyüğe Lamba-1 kullanan, LED çipli, Lamba-3 kullanan ve Lamba-2 kullanan armatürler şeklindedir. THD sınırlarını belirleyen ulusal bir standart bulunmamaktadır. Elektrik ve Elektronik Mühendisleri Enstitüsü (IEEE, 2014) ise $1 \mathrm{kV}$ ve altı sistemlerde THD değerinin \% 8 'in altında olması gerektiğini belirtmektedir. IEEE kabulü referans alındığında; bekleme durumunda tüm armatürler bu THD değerinin üzerine çıkmakta; çalışma durumunda ise sadece Lamba-1 kullanan armatürler bu değerin altında THD değerine sahip olmaktadırlar.

Son olarak, PIR sensörlü armatürlerin 1şıksal değerleri ölçülmüş olup, ölçüm sonuçları Çizelge 5 'te verilmiştir. Burada birim W başına üretilen 1şık akısı değeri olan etkinlik faktörü $(\mathrm{lm} / \mathrm{W})$, 1şıksal ölçümlerdeki değerlendirme parametremiz olacaktır. Sonuçlar incelendiğinde düşük enerji tüketimleri ve yüksek ışık akısı vermeleri sebebiyle etkinliği en yüksek armatürler LED çipli armatürler olarak karşımıza çıkmaktadır. LED çipli armatürleri Lamba-2'den daha düşük 1şık akısı üretmesine rağmen yine daha az enerji tüketerek daha verimli olan Lamba-3 kullanan armatürler izlemektedir. Lamba-3 kullanan armatürleri Lamba-2 kullanan armatürler izlemektedir. Lamba-1 kullanan armatürler ise etkinlik değeri konusunda diğer alternatiflerin epeyce gerisinde kalmaktadırlar. 
Avrupa Bilim ve Teknoloji Dergisi

Çizelge 5. Armatürlerin ışıksal ölçüm sonuçları

\begin{tabular}{|c|c|c|c|c|c|c|}
\hline No. & $\begin{array}{l}\text { Armatür } \\
\text { Cinsi }\end{array}$ & Lamba & $\begin{array}{c}\text { Üretilen } \\
\text { Toplam } \\
\text { Işık Akısı } \\
\text { (lm) }\end{array}$ & $\operatorname{LOR}(\%)$ & $\begin{array}{c}\text { Armatürden } \\
\text { Yayılan Işık } \\
\text { Akısı (lm) }\end{array}$ & $\begin{array}{c}\text { Etkinlik } \\
(\mathrm{lm} / \mathrm{W})\end{array}$ \\
\hline 1 & Armatür-1 & Lamba-1 & 511,32 & $68,60 \%$ & 350,77 & 6,22 \\
\hline 2 & Armatür-1 & Lamba-2 & 1610,24 & $66,40 \%$ & 1069,2 & 53,54 \\
\hline 3 & Armatür-1 & Lamba-3 & 1330,8 & $67,30 \%$ & 895,63 & 55,15 \\
\hline 4 & Armatür-2 & Lamba-1 & 511,32 & $65,60 \%$ & 335,43 & 5,98 \\
\hline 5 & Armatür-2 & Lamba-2 & 1610,24 & $64,10 \%$ & 1032,16 & 51,71 \\
\hline 6 & Armatür-2 & Lamba-3 & 1330,8 & $64,40 \%$ & 857,04 & 52,81 \\
\hline 7 & Armatür-3 & Lamba-1 & 511,32 & $42,40 \%$ & 216,8 & 3,86 \\
\hline 8 & Armatür-3 & Lamba-2 & 1610,24 & $43,20 \%$ & 695,62 & 35,55 \\
\hline 9 & Armatür-3 & Lamba-3 & 1330,8 & $44,20 \%$ & 588,21 & 37,06 \\
\hline 10 & Armatür-4 & Lamba-1 & 511,32 & $48,30 \%$ & 246,97 & 4,41 \\
\hline 11 & Armatür-4 & Lamba-2 & 1610,24 & $49,70 \%$ & 800,29 & 41,36 \\
\hline 12 & Armatür-4 & Lamba-3 & 1330,8 & $50,30 \%$ & 669,39 & 42,72 \\
\hline 13 & Armatür-5 & Lamba-1 & 511,32 & $63,00 \%$ & 322,13 & 5,76 \\
\hline 14 & Armatür-5 & Lamba-2 & 1610,24 & $62,50 \%$ & 1006,4 & 52,28 \\
\hline 15 & Armatür-5 & Lamba-3 & 1330,8 & $64,10 \%$ & 853,04 & 54,79 \\
\hline 16 & Armatür-6 & Lamba-1 & 511,32 & $50,60 \%$ & 258,73 & 4,64 \\
\hline 17 & Armatür-6 & Lamba-2 & 1610,24 & $50,90 \%$ & 819,61 & 42,42 \\
\hline 18 & Armatür-6 & Lamba-3 & 1330,8 & $52,10 \%$ & 693,35 & 44,3 \\
\hline 19 & Armatür-7 & Lamba-1 & 511,32 & $42,00 \%$ & 214,75 & 3,82 \\
\hline 20 & Armatür-7 & Lamba-2 & 1610,24 & $42,90 \%$ & 690,79 & 35,61 \\
\hline \begin{tabular}{|l|}
21 \\
\end{tabular} & Armatür-7 & Lamba-3 & 1330,8 & $43,80 \%$ & 582,89 & 37,03 \\
\hline 22 & Armatür-8 & Lamba-1 & 511,32 & $46,80 \%$ & 239,3 & 4,3 \\
\hline 23 & Armatür-8 & Lamba-2 & 1610,24 & $46,60 \%$ & 750,37 & 38,62 \\
\hline 24 & Armatür-8 & Lamba-3 & 1330,8 & $47,20 \%$ & 628,14 & 39,88 \\
\hline 25 & Armatür-9 & Lamba-1 & 511,32 & $46,00 \%$ & 235,21 & 4,17 \\
\hline 26 & Armatür-9 & Lamba-2 & 1610,24 & $48,40 \%$ & 779,36 & 40,11 \\
\hline 27 & Armatür-9 & Lamba-3 & 1330,8 & $49,50 \%$ & 658,75 & 41,85 \\
\hline 28 & Armatür-10 & Lamba-1 & 511,32 & $50,60 \%$ & 258,73 & 4,61 \\
\hline 29 & Armatür-10 & Lamba-2 & 1610,24 & $51,70 \%$ & 832,49 & 43,29 \\
\hline 30 & Armatür-10 & Lamba-3 & 1330,8 & $52,10 \%$ & 693,35 & 44,53 \\
\hline 31 & Armatür-11 & - & 673,32 & $100,00 \%$ & 673,32 & 89,78 \\
\hline 32 & Armatür-12 & - & 629,85 & $100,00 \%$ & 629,85 & 86,28 \\
\hline 33 & Armatür-13 & - & 480,15 & $100,00 \%$ & 480,15 & 60,02 \\
\hline 34 & Armatür-14 & - & 1062,9 & $100,00 \%$ & 1062,9 & 139,86 \\
\hline
\end{tabular}

LOR (Light output ratio) değeri, armatürden çıkan toplam ışık miktarının oranını \% cinsinden ifade etmektedir. E27 duylu armatürlerde bu değer açılı 1şıkölçer test sisteminde ölçülmüş ve ölçüm sonuçları Çizelge 5'te verilmiştir. LED'li armatürlerde LOR değeri Uluslararası Aydınlatma Komisyonu (CIE) tarafından \% 100 olarak kabul edilmiştir. Bu sebeple LED çipli armatürlerde bu değer \%100 olarak alınmıştır. Lamba kullanılan E27 duylu modellerde LOR değerinin \%100'den küçük çıkmasının temel nedeni lambaların $360^{\circ}$ 1şık vermesinden ötürü üretilen ışık miktarının tamamının armatürden dışarı çıkamamasıdır.

Armatür camının fiziksel özelliği LOR değerini ve buna paralel olarak etkinlik değerini doğrudan etkilemektedir. Aynı 1şık kaynağının kullanıldığı farklı armatürlerde gözlenen farklar genel itibariyle armatür camından kaynaklanmaktadır. Tüm armatürlerin camı buzludur. Buna ek olarak Armatür-3, Armatür-4, Armatür-6, Armatür-7, Armatür-8, Armatür-9, Armatür-10'un camları hem buzlu hem de boyalıdır. Camları boyasız olan ve aynı 1şık kaynakları kullanılmış Armatür-1, Armatür-2, Armatür-5 incelendiğinde bu armatürlerin LOR ve etkinlik değerlerinin camları boyalılardan daha yüksek oldukları tespit edilmiştir.

Tüm armatürlerin ışın açıları geniş açıdır ve $101,2^{\circ}-148,6^{\circ}$ arasında değişmektedir. LED çipli armatürler doğrudan aşağı yönlü 1şık verdikleri için açı değerleri E27 duylu armatürlerden daha dardır. (LED çipli armatürler 101,2 ${ }^{\circ}-109,1^{\circ}$ arası, E27 duylu armatürler $114,2^{\circ}-148,6^{\circ}$ ) E27 duylu armatürlerde kullanılan lambalar $360^{\circ}$ 1şık verdikleri için daha geniş açıda 1şık verirler. Armatürlerde 1şınları düzenleyici bir reflektör bulunmaması armatürlerde karşılaşılan geniş açının temel sebebidir. Ayrıca E27 duylu armatürlerde kullanılan farklı lambalarla farklı ışın açıları elde edilmiştir. Bunun temel sebebi lamba çaplarının farklı olmasıdır.

\section{PIR Sensörlü Armatürlerin Ekonomik Analizi}

Ekonomik analiz ömür maliyet analizi (LCCA) metodu ile yapılmıştır (Ayaz, 2017). LCCA metoduna göre toplam maliyet (TC) Eşitlik 1 ile hesaplanır.

$$
T C=I C+M C+E C-S V
$$

IC montaj maliyetini, MC bakım maliyetini, EC enerji maliyetini, SV hurda değerini ifade etmektedir.

Analiz için toplam süre armatürlerin efektif olarak kullanılabileceği süre olan 10 yıl olarak alınmıştır. Bu süre zarfında her armatürün günde 4 saat çalışacağı, 20 saat beklemede kalacağı, 25 kere de açılıp kapanacağı öngörülmüştür. 


\section{European Journal of Science and Technology}

IC değeri için armatürlerin satın alma maliyeti dikkate alınacaktır. Tüm armatürlerin montaj şekli aynı olduğu için montaj iş̧iliği analize dahil edilmeyecektir. Satın alma maliyeti E27 duylu armatürler için ortalama 50TL/adet, LED çipli armatürler için de ortalama 100TL/adettir.

MC değeri için yalnız E27 duylu armatürlerde kullanılacak lamba maliyeti dikkate alınacaktır. LED çipli armatürler bu süre zarfinda herhangi bir LED çip veya parça değişimine ihtiyaç duymamaktadırlar. Bakım sebebiyle yapılacak temizlik ve diğer kontroller tüm armatürlerde aynı olacağı için analize dahil edilmeyecektir.

Lamba-1'in fiyatı 5,50TL/adettir. Kullanım ömrü 2000 saat, açma kapama sayısı da 8000 adettir. Bu sebeple kullanım ömrü, açma kapama sayısına bağlıdır ve analiz süresi boyunca $12 \mathrm{kez}$ lamba değişilmesi gerekir. Buna göre toplam lamba maliyeti 132,00TL olmaktadır.

Lamba-2'nin fiyatı 10,30TL/adettir. Kullanım ömrü 15000 saat, açma kapama sayısı da 150000 adettir. Bu sebeple kullanım ömrü, lamba ömrüne bağlıdır ve analiz süresi boyunca lamba değişilmesi gerekmez. Buna göre toplam lamba maliyeti 20,60TL olmaktadır.

Lamba-3'ün fiyatı 10,35TL/adettir. Kullanım ömrü 25000 saat, açma kapama sayısı da 50000 adettir. Bu sebeple kullanım ömrü, açma kapama sayısına bağlıdır ve analiz süresi boyunca $1 \mathrm{kez}$ lamba değişilmesi gerekir. Buna göre toplam lamba maliyeti 41,40TL olmaktadır.

EC değeri için yıllık kullanım ve bekleme süresine göre armatürlerin yıllık enerji tüketim miktarları hesaplanır. Hesaplanan tüketim miktarları enerji birim fiyatı (vergiler dahil İstanbul Anadolu Yakası Ağustos 2018 perakende tek zamanlı enerji tüketim birim fiyatı olan 0,485877TL/kWh kullanılmıştır) ile çarpılarak yıllık enerji maliyeti bulunur. Bulunan yıllık enerji maliyeti enflasyon oranı (e) (TCMB Enflasyon Verileri Tüketici Fiyatları, 2018) ve faiz oranı (i) (TCMB Kredi ve Mevduatlara Uygulanan Ağırlıklı Ortalama Faiz Oranları, 2018) parametrelerinin analize dahil edildiği Eşitlik 2 vasıtasıyla 10 yıllık toplam tüketim bedelinin şimdiki değerine çevirilir.

$E C($ şimdiki de ğer $)=E C *(1+e) * \frac{1-\left(\frac{1+e}{1+i}\right)^{10}}{i-e}$

Eşitlik 2 vasıtasıyla hesaplanan 10 yıllık toplam enerji maliyetleri Çizelge 6'da verilmiştir. 


\section{Avrupa Bilim ve Teknoloji Dergisi}

Çizelge 6. Armatürlerin 10 ylllık toplam enerji maliyetleri

\begin{tabular}{|c|c|c|c|c|c|}
\hline No. & $\begin{array}{l}\text { Armatür } \\
\text { Cinsi }\end{array}$ & Lamba & $\begin{array}{c}\text { Yıllık } \\
\text { Tüketim } \\
\text { Toplamı } \\
\text { (kWh) }\end{array}$ & $\begin{array}{c}\text { Yıllık } \\
\text { Tüketim } \\
\text { Tutarı } \\
\text { (TL) }\end{array}$ & $\begin{array}{c}\text { Toplam } \\
\text { Enerji } \\
\text { Maliyeti } \\
\text { Şimdiki } \\
\text { Değeri } \\
\text { (TL) } \\
\end{array}$ \\
\hline 1 & Armatür-1 & Lamba-1 & 91,03 & 44,23 & 529,54 \\
\hline 2 & Armatür-1 & \begin{tabular}{|l|} 
Lamba-2 \\
\end{tabular} & 37,92 & 18,42 & 220,56 \\
\hline 3 & Armatür-1 & Lamba-3 & 32,47 & 15,78 & 188,88 \\
\hline 4 & Armatür-2 & Lamba-1 & 89,94 & 43,70 & 523,17 \\
\hline 5 & Armatür-2 & Lamba-2 & 37,17 & 18,06 & 216,23 \\
\hline 6 & Armatür-2 & Lamba-3 & 31,73 & 15,41 & 184,55 \\
\hline 7 & Armatür-3 & Lamba-1 & 88,24 & 42,87 & 513,32 \\
\hline 8 & Armatür-3 & Lamba-2 & 34,78 & 16,90 & 202,30 \\
\hline 9 & Armatür-3 & Lamba-3 & 29,38 & 14,27 & 170,88 \\
\hline 10 & Armatür-4 & Lamba-1 & 86,90 & 42,22 & 505,50 \\
\hline 11 & Armatür-4 & \begin{tabular}{|l|} 
Lamba-2 \\
\end{tabular} & 33,36 & 16,21 & 194,06 \\
\hline 12 & Armatür-4 & Lamba-3 & 27,99 & 13,60 & 162,81 \\
\hline 13 & Armatür-5 & Lamba-1 & & 42,18 & 504,99 \\
\hline 14 & Armatür-5 & Lamba-2 & 33,22 & 16,14 & 193,22 \\
\hline 15 & Armatür-5 & Lamba-3 & 27,84 & 13,53 & 161,96 \\
\hline 16 & Armatür-6 & Lamba-1 & 86,46 & 42,01 & 502,95 \\
\hline 17 & Armatür-6 & Lamba-2 & 33,32 & 16,19 & 193,81 \\
\hline 18 & Armatür-6 & Lamba-3 & 27,96 & 13,58 & 162,64 \\
\hline 19 & Armatür-7 & Lamba-1 & 87,91 & 42,71 & 511,36 \\
\hline 20 & Armatür-7 & Lamba-2 & 34,16 & 16,60 & 198,74 \\
\hline 21 & Armatür-7 & Lamba-3 & 28,82 & 14,00 & 167,65 \\
\hline 22 & Armatür-8 & \begin{tabular}{|l|} 
Lamba-1 \\
\end{tabular} & 87,12 & 42,33 & 506,78 \\
\hline 23 & Armatür-8 & Lamba-2 & 34,21 & 16,62 & 198,99 \\
\hline 24 & Armatür-8 & Lamba-3 & 28,84 & 14,01 & 167,74 \\
\hline 25 & Armatür-9 & Lamba-1 & 88,26 & 42,88 & 513,40 \\
\hline 26 & Armatür-9 & Lamba-2 & 34,21 & 16,62 & 198,99 \\
\hline 27 & Armatür-9 & Lamba-3 & 28,82 & 14,00 & 167,65 \\
\hline 28 & Armatür-10 & \begin{tabular}{|l|} 
Lamba-1 \\
\end{tabular} & 86,34 & 41,95 & 502,28 \\
\hline 29 & Armatür-10 & Lamba-2 & 32,46 & 15,77 & 188,80 \\
\hline 30 & Armatür-10 & Lamba-3 & 27,11 & 13,17 & 157,71 \\
\hline 31 & Armatür-11 & - & 18,25 & 8,87 & 106,16 \\
\hline 32 & Armatür-12 & - & 15,77 & 7,66 & 91,72 \\
\hline 33 & Armatür-13 & - & 18,98 & 9,22 & 110,41 \\
\hline 34 & Armatür-14 & - & 16,57 & 8,05 & 96,40 \\
\hline
\end{tabular}

10 yıllık kullanım süresi sonunda armatürlerin ekonomik değerinin kalmayacağı öngörülmektedir. Bu sebeple SV değeri sıfir olarak alınmış ve Eşitlik 1'de işleme dahil edilmemiştir.

10 yıllık analiz süresince armatürlerin toplam maliyetleri Çizelge 7'de verilmiştir. Ekonomik analiz sonucuna göre en ekonomik armatür seçeneği LED çipli armatürler olmaktadır. LED çipli armatürleri ekonomi bakımından LED lamba (Lamba-2 ve Lamba-3) takılı armatürler izlemektedir. Lamba-3 takılı alternatifler, Lamba-2 takılılarda bir miktar daha fazla ekonomiktir. Lamba-1 takılı armatürler ise ekonomi konusundaki en kötü seçenektir. Bu armatürler LED çipli armatürlerin 3 katından, LED lambalı alternatiflerin ise 2 katından daha yüksek bir maliyete sebep olmaktadırlar. 
Çizelge 7. Armatürlerin toplam maliyetleri

\begin{tabular}{|c|c|c|c|c|c|c|}
\hline No. & $\begin{array}{l}\text { Armatür } \\
\text { Cinsi }\end{array}$ & Lamba & $\begin{array}{c}(\text { IC) } \\
\text { Kurulum } \\
\text { Maliyeti } \\
\text { (TL) }\end{array}$ & $\begin{array}{c}\text { (MC) } \\
\text { Bakım } \\
\text { (Lamba) } \\
\text { Maliyeti } \\
\text { (TL) }\end{array}$ & $\begin{array}{c}(\mathrm{EC}) \\
\text { Enerji } \\
\text { Maliyeti } \\
\text { (TL) }\end{array}$ & $\begin{array}{c}\text { (TC) } \\
\text { Toplam } \\
\text { Maliyet } \\
\text { (TL) }\end{array}$ \\
\hline 1 & Armatür-1 & Lamba-1 & 50,00 & 132,00 & 529,54 & 711,54 \\
\hline 2 & Armatür-1 & Lamba-2 & 50,00 & 20,60 & 220,56 & 291,16 \\
\hline 3 & Armatür-1 & Lamba-3 & 50,00 & 41,40 & 188,88 & 280,28 \\
\hline 4 & Armatür-2 & Lamba-1 & 50,00 & 132,00 & 523,17 & 705,17 \\
\hline 5 & Armatür-2 & Lamba-2 & 50,00 & 20,60 & 216,23 & 286,83 \\
\hline 6 & Armatür-2 & Lamba-3 & 50,00 & 41,40 & 184,55 & 275,95 \\
\hline 7 & Armatür-3 & Lamba-1 & 50,00 & 132,00 & 513,32 & 695,32 \\
\hline 8 & Armatür-3 & Lamba-2 & 50,00 & 20,60 & 202,30 & 272,90 \\
\hline 9 & Armatür-3 & Lamba-3 & 50,00 & 41,40 & 170,88 & 262,28 \\
\hline 10 & Armatür-4 & Lamba-1 & 50,00 & 132,00 & 505,50 & 687,50 \\
\hline 11 & Armatür-4 & Lamba-2 & 50,00 & 20,60 & 194,06 & 264,66 \\
\hline 12 & Armatür-4 & Lamba-3 & 50,00 & 41,40 & 162,81 & 254,21 \\
\hline 13 & Armatür-5 & Lamba-1 & 50,00 & 132,00 & 504,99 & 686,99 \\
\hline 14 & Armatür-5 & Lamba-2 & 50,00 & 20,60 & 193,22 & 263,82 \\
\hline 15 & Armatür-5 & Lamba-3 & 50,00 & 41,40 & 161,96 & 253,36 \\
\hline 16 & Armatür-6 & Lamba-1 & 50,00 & 132,00 & 502,95 & 684,95 \\
\hline 17 & Armatür-6 & Lamba-2 & 50,00 & 20,60 & 193,81 & 264,41 \\
\hline 18 & Armatür-6 & Lamba-3 & 50,00 & 41,40 & 162,64 & 254,04 \\
\hline 19 & Armatür-7 & Lamba-1 & 50,00 & 132,00 & 511,36 & 693,36 \\
\hline 20 & Armatür-7 & Lamba-2 & 50,00 & 20,60 & 198,74 & 269,34 \\
\hline 21 & Armatür-7 & Lamba-3 & 50,00 & 41,40 & 167,65 & 259,05 \\
\hline 22 & Armatür-8 & Lamba-1 & 50,00 & 132,00 & 506,78 & 688,78 \\
\hline 23 & Armatür-8 & Lamba-2 & 50,00 & 20,60 & 198,99 & 269,59 \\
\hline 24 & Armatür-8 & Lamba-3 & 50,00 & 41,40 & 167,74 & 259,14 \\
\hline 25 & Armatür-9 & Lamba-1 & 50,00 & 132,00 & 513,40 & 695,40 \\
\hline 26 & Armatür-9 & Lamba-2 & 50,00 & 20,60 & 198,99 & 269,59 \\
\hline 27 & Armatür-9 & Lamba-3 & 50,00 & 41,40 & 167,65 & 259,05 \\
\hline 28 & Armatür-10 & Lamba-1 & 50,00 & 132,00 & 502,28 & 684,28 \\
\hline 29 & Armatür-10 & Lamba-2 & 50,00 & 20,60 & 188,80 & 259,40 \\
\hline 30 & Armatür-10 & Lamba-3 & 50,00 & 41,40 & 157,71 & 249,11 \\
\hline 31 & Armatür-11 & - & 100,00 & 0,00 & 106,16 & 206,16 \\
\hline 32 & Armatür-12 & - & 100,00 & 0,00 & 91,72 & 191,72 \\
\hline 33 & Armatür-13 & - & 100,00 & 0,00 & 110,41 & 210,41 \\
\hline 34 & Armatür-14 & - & 100,00 & 0,00 & 96,40 & 196,40 \\
\hline
\end{tabular}

\section{Bulgular ve Tartışma}

Elektriksel ve 1şıksal analizlerin sonucuna göre en verimli PIR sensörlü armatürün LED çipli armatürler olduğu tespit edilmiştir. PIR sensörlü armatürleri LED lamba kullanılan E27 duylu armatürler izlemektedir. E27 duylu armatürlerde halojen lamba kullanılması ise en düşük verimli armatür/şsık kaynağı kombinasyonudur.

Ekonomik analiz sonuçları da elektriksel ve 1şıksal analiz sonuçlarına paralel olarak gerçekleşmiştir. Buna göre en ekonomik PIR sensörlü armatür seçeneği LED çipli armatürlerdir. LED çipli armatürleri yine E27 duylu armatürlerde LED lamba kullanımı izlemektedir. E27 duylu armatürlerde halojen lamba kullanımı ise en maliyetli çözümdür. E27 duylu armatürlerin ve halojen lambaların ilk satın alma maliyeti düşük olduğu için kullanıcılara ilk başta cazip gelmektedir ve çoğunlukla tercih sebebi olabilmektedirler. Ancak zaman içinde yüksek enerji tüketim bedelleri ve kısa halojen lamba ömrü sebebiyle kullanım süresi boyunca LED lamba kullanımından 2 kat, LED çipli armatür kullanımından ise 3 kat daha maliyetli olmaktadırlar. Buradan hareketle, bir projede ilk kez armatür kurulumu yapılacaksa LED çipli armatürlerin tercih edilmesi gerekir. Şayet mevcut armatürlerin lambaları değiştirilecekse de LED lambalar tercih edilmeli ve halojen lambalardan kaçınılmalıdır.

PIR sensörlü armatür seçimi yapılırken ön camı boyasız bir model seçmek özellikle E27 duylu armatürlerde önem arzetmektedir. Boyalı camlar armatürden çıkan ışık miktarını düşürdükleri için ışıksal verimde düşüşe neden olurlar. Daha yüksek ışıksal verim için camı boyasız olan armatürler tercih edilmelidir.

PIR sensörlü armatürlerin tamamı reflektörsüz tiptedir. Armatürlere reflektör ilavesi özellikle E27 duylu armatürlerde armatürden çıkacak ışık miktarının artmasına ve ışıksal verimin yükselmesine yardımcı olabilir. Ayrıca reflektör ilavesi, yüksek tavan montajı durumunda armatürün ışıksal performansına da olumlu katkı sağlar. 


\section{Kaynaklar}

Hasan, K. M. M., Rahman, M. S. ve Rafiq, M. A., (2017). "Experimental Analysis of Harmonic and Power Factor for Various Lighting Loads", 2017 3rd International Conference on Electrical Information and Communication Technology (EICT), 7-9 Aral1k 2017, Khulna.

Oliveira, G. S., Oliveira, E. P., Silva, A. P. ve Carvalho, C. C. M. M., (2016). "Power Quality of LED Lamps", 2016 17th International Conference on Harmonics and Quality of Power (ICHQP), 16-19 Ekim 2016, Minas Gerais.

Raditschova, J. ve Gasparovsky, D., (2016). "LED retrofits and their role in transient to the more energy efficient home lighting", 2016 IEEE Lighting Conference of the Visegrad Countries (Lumen V4), 13-16 Eylül 2016, Karpacz.

Raimondi, F. M., Curto, D., Frazitta, V. ve Miloner, D., (2018). "Energy savings for indoor lighting in a shopping mall: a case of study", 2018 Thirteenth International Conference on Ecological Vehicles and Renewable Energies (EVER), 10-12 Nisan 2018, Monaco.

Oleksijs, R. ve Sauhatas, A., (2016). "Hallways and Stairways Lighting System Cost Reduction", 57th International Scientific Conference on Power and Electrical Engineering of Riga Technical University (RTUCON), 13-14 Ekim 2016, Riga \& Cesis.

Tsai, C. H., Bai, Y. W., Chu, C. A., Chung, C. Y. ve Lin, M. B., (2011). "PIR-sensor-based Lighting Device with Ultra-low Standby Power Consumption", IEEE Transactions on Consumer Electronics, Vol.57, No.3: 1157-1164.

Tsai, C. H., Bai, Y. W., Lin, M. B., Chung, C. Y. ve Jhang, R. J. R., (2013). "Design and Implementation of a PIR Luminaire with Zero Standby Power Using a Photovoltaic Array”, 2013 IEEE International Conference on Consumer Electronics (ICCE), 11-14 Ocak 2013, Nevada.

Juntunen, E., Sarjanoja, E., Eskeli, J., Pihlajaniemi, H. ve Österlund, T., (2018). "Smart and dynamic route lighting control based on movement tracking", Building and Enviroment, 142: 472-483.

IEEE. (2014). IEEE Recommended Practice and Requirements for Harmonic Control in Electric Power Systems (Standard No. IEEE 519-2014). Retrieved from https://standards.ieee.org/content/ieee-standards/en/standard/519-2014.html

Ayaz, R., (2017). Led ve Konvansiyonel Işık Kaynaklı Yol Aydınlatma Armatürlerinin Işıksal, Elektriksel ve Ekonomik Açıdan İncelenmesi, Doktora Tezi, YTÜ Fen Bilimleri Enstitüsü, İstanbul.

TCMB Enflasyon Verileri Tüketici Fiyatları, http://www.tcmb.gov.tr/wps/wcm/connect/TR/TCMB+TR/Main+Menu/Istatistikler/Enflasyon+Verileri/Tuketici+Fiyatlari , 9 Kasim 2018.

TCMB Kredi ve Mevduatlara Uygulanan Ağırlıklı Ortalama Faiz Oranları, http://www.tcmb.gov.tr/wps/wcm/connect/TR/TCMB\%20TR/Main\%20Menu/Istatistikler/Secilmis\%20Grafikler/Parasal\%20ve\% 20Finansal\%20Istatistikler/Kredi\%20ve\%20Mevduatlara\%20Uygulanan\%20Agirlikli\%20Ortalama\%20Faiz\%20Oranlari , 9 Kasim 2018 